SALUD

Ciencias sociales

HUMANIDADES

MAS ALLÁ DE LOS COMITÉS DE ÉTICAASISTENCIAL:

HACIA UNA CULTURA BIOÉTICA

-BEGOÑA ROMÁN 1

\title{
PENSAMIENTO ACTUAL
}

PROLEGÓMENOS PARA UNA FILOSOFÍA DE LA ENFERMEDAD.

- MARCO SANZ.

JOSÉ DE LETAMENDI, FUNDAMENTO DE SU CIENCIA Y CAUSA DE SU DESPRESTIGIO

- EMILIO CERVANTES 36

\section{ARTE, SALUD Y SOCIEDAD}

TODOS POSEEMOS INTELIGENCIA MUSICAL 
Co-directores

Marc Antoni Broggi i Trias (PCBC)

Francesc Borrell (UB)

\section{Jefa de Redacción}

Núria Estrach (UAB)

\section{Consejo científico}

Juan Carlos Hernández Clemente

Juan Medrano Albéniz

Vicente Morales Hidalgo

\section{Correspondencia \\ Web:}

http://www.fundacionletamendi.com

Correo electrónico:

info@fundacionletamendi.com

\section{Envío de manuscritos:}

http://www.fundacionletamendi.com/revista-foliahumanistica/envio-de-manuscritos/

\section{Información editorial}

Folia Humanística publica artículos por encargo solicitados a especialistas, así como aquellas propuestas enviadas por los autores y aceptadas tras su evaluación por pares de académicos especializados.

Los textos recibidos se publicarán en la lengua original (castellano, catalán, inglés y francés); los que se consideren de relevancia mayor serán traducidos al inglés y castellano.

Los artículos deben ser originales y acompañados del documento "derechos de autor" que encontrarán en la web, junto a las normas de presentación a seguir.

Cada artículo publicado al final tendrá especificado la referencia de citación, donde se incluirá el número $\mathrm{DOI}{ }^{\circledR}$.

\section{Distribución}

La Revista Folia Humanística es de libre acceso a consultar online.

http://www.fundacionletamendi.com/category/rev

istal

Folia Humanística es una revista internacional que tiene el doble objetivo de fomentar, por un lado, la reflexión y el debate público en el ámbito de la Salud, Ciencias Sociales y Humanidades, y por el otro, la colaboración entre distintos equipos de investigación nacionales e internacionales que dinamicen el diálogo entre la filosofía de la medicina, la salud pública y la justicia social. Dividida en "Tema del día", (artículos para el debate), "Pensamiento actual", (artículos críticos de novedades editoriales), y "Arte, Salud y Sociedad", la revista se esfuerza en fortalecer las conexiones entre la investigación académica, la práctica clínica, las experiencias de los pacientes y sus implicaciones éticas y estéticas en la sociedad. Todo ello con la intención de favorecer la reflexión entre diferentes disciplinas sobre temas de actualidad y las tendencias más novedosas en el campo de las Humanidades y la Salud.

Folia Humanística is an International Journal, born with the dual aim of fuelling the discussion and public debate on issues of health, social sciences and humanities and on the hand, of fostering cooperation between various research groups, both national and International, to spur the dialogue between philosophy and medicine, public health and social justice. The Journal is divided into three different sections: "main focus" (article for debate), "Contemporary thought" (critical reviews of new Publications) and "Arts, Health and Society" which all contribute to strengthening the links between academic research, clinical practice, the experience of patients and their ethical and esthetical implications for society. Ultimately, the intention of the Journal is to promote reflection at the crossroads of several disciplines on topical issues and new trends in humanities and health. 


\section{JOSÉ DE LETAMENDI: FUNDAMENTO DE SU CIENCIA Y CAUSA DE SU DESPRESTIGIO}

\section{Emilio Cervantes}

Resumen: José de Letamendi ha recibido un trato variado a lo largo de la historia, con críticas negativas de Pio Baroja, Gregorio Marañón y Pedro Laín Entralgo. Letamendi fue profesor de Baroja, a quien suspendió en la Facultad de Medicina de la Universidad de Madrid. Y éste último, gran amigo de Marañón, hombre de gran relevancia, por lo que buena parte de su crítica negativa puede tener origen en esa relación con Baroja.

No obstante, cabe recordar que Letamendi fue un erudito y su amplia labor científica tuvo un fundamento explícito. La base religiosa de Letamendi y su profundo conocimiento de la Filosofía de la Ciencia se ponen de manifiesto en el discurso de apertura del curso 18781879 en la Universidad de Barcelona. Al contrario de lo que expresó Baroja, Letamendi tenía ideas muy firmes sobre la ciencia que, en el panorama científico actual, es necesario poner de relieve junto con las características principales de su mentalidad científica.

Palabras clave: educación/ medicina/ religión/ romanticismo/ tradicionalismo.

\section{Abstract: JOSÉ DE LETAMENDI: FOUNDATION OF ITS SCIENCE AND CAUSE OF ITS DISCRIMINATION}

José de Letamendi has received a varied treatment throughout history with negative criticism from Pío Baroja, Gregorio Marañón and Pedro Laín Entralgo. Given the relevance of the second and his friendship with Baroja, some of the negative criticism has its origin in his personal relationship with Baroja, of whom Letamendi was a professor and whom he failed at the Faculty of Medicine of the University of Madrid.

But Letamendi was a scholar and his extensive scientific work had an explicit foundation. Letamendi's religious basis and his deep knowledge of the Philosophy of Science are shown in the opening speech of the academic year 1878-1879 at the University of Barcelona. Contrary to what Baroja said, Letamendi had very firm ideas about science that, in today's scientific panorama, need to be highlighted along with the main characteristics of his scientific mentality.

Keywords: education/ medicine/ religión/ romanticism/ traditionalism.

Artículo recibido: 10 febrero 2020; aceptado: 1 junio 2020 . 


\section{INTRODUCCIÓN}

José de Letamendi Manjarrés (Barcelona, 1828- Madrid, 1897) fue un médico católico de amplia formación humanista y filosófica. Catedrático de Anatomía en la Universidad de Barcelona (1857-1878) y de Patología en la de Madrid (1878-1897), compaginó la práctica y la docencia de la medicina con diversas actividades académicas y artísticas. Se ha dicho de Letamendi que es "sin duda alguna, el médico español del siglo XIX más discutido y tal vez el más discutible" (Palafox, 1965). Queda pendiente, no obstante, analizar si las críticas negativas recibidas se han basado, o no, en el análisis metódico de su obra. O si, por el contrario, han sido simplemente opiniones, $\forall$ puntos de vista incompletos y subjetivos, resultado del enfrentamiento personal directo con su alumno, Pío Baroja. La ausencia de argumentos metódicos en las críticas, nos lleva a pensar que otro de los motivos para ésta pudo ser su catolicismo, expresado tenazmente, junto a su universalidad, que no conoce límites entre disciplinas. Un breve resumen de su trayectoria personal y profesional servirá de preludio antes de prestar atención a algunas críticas recibidas a lo largo de los años. Con el mismo propósito, analizaremos en detalle la conferencia de apertura del curso 1878-1879 en la Universidad de Barcelona, titulada Valor de los estudios anatómicos en el movimiento intelectual contemporáneo.

\section{TRAYECTORIA PERSONAL DE JOSÉ DE LETAMENDI ${ }^{1}$}

\subsection{FAMILIA Y EDUCACIÓN}

José de Letamendi y Manjarrés era hijo de José de Letamendi y Borés, de antigua familia vasca y de profesión Comisario de Guerra, y doña Mariana de Manjarrés y Valdés, de estirpe riojana. Huérfano de padre desde la temprana edad de ocho meses. Siempre fue aplicado en los estudios, obteniendo la calificación de sobresaliente y matrícula gratis en los cuatro cursos de Gramática y Retórica latina en

\footnotetext{
${ }^{1}$ Algunos datos para esta sección se han tomado de un capítulo dedicado a Letamendi en La llustración Española y Americana (15-VI-1871), una nota necrológica aparecida en La Gaceta de Instrucción Pública del 15 de julio de 1897 y la web Auñamendi Eusko Entziklopedia (http://aunamendi.euskoikaskuntza.eus/eu/letamendi-y-manjarres-jose-de/ar-80726/; consultada el 13/12/2019).
} 


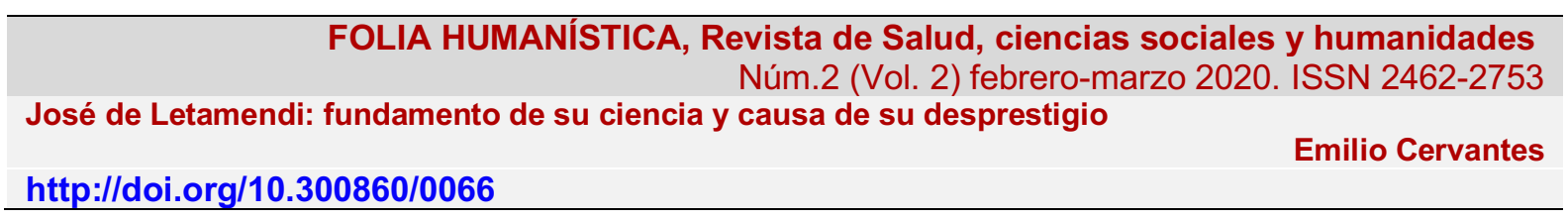

el Seminario Conciliar de Barcelona. Estudió tres años de Filosofía y, posteriormente, cursó la carrera de Medicina en la Universidad de Barcelona (entre 1845 y 1852). Ejerció como segundo ayudante de Anatomía, dando repasos de la asignatura de Anatomía y disección, y, de este modo, atendió a las necesidades de su familia. Parece que en una ocasión afirmó faltarle exclusivamente, como papel a desempeñar en la cátedra de Anatomía, el de cadáver.

\subsection{ACTIVIDAD PROFESIONAL EN EL EJERCICIO DE LA MEDICINA}

En 1854 ganó por oposición la plaza de primer ayudante de la cátedra de Anatomía. En 1857 obtuvo la cátedra en propiedad que conservó hasta 1878, cuando ganó por concurso la de Patología General del Colegio de San Carlos en la Universidad Central de Madrid.

Por su labor durante las epidemias de cólera de 1854 y 1865 fue recompensado con la Cruz de Beneficencia de primera clase.

Entre 1860 y 1878 fue Presidente del Ateneo y del Instituto Médico de Barcelona; fundador del primer establecimiento dinamo-terápico de España y de la primera Sociedad Española de inoculación directa de la linfa vacuna; descubrió en 1875 el método para obtener la anestesia local en las operaciones quirúrgicas y, al año siguiente, inventó un nuevo método operatorio; fundó y dirigió varios periódicos profesionales.

En Madrid desempeñó los cargos de decano en la Facultad de Medicina, senador del reino por Tarragona (1889), consejero de Instrucción Pública, vocal del Real Colegio de Sanidad y académico de número de la Real Academia de Medicina.

\subsection{OBRA CIENTÍFICA}

Su obra comprende libros de texto como el Curso de Patología General, el Plan de Reforma de la Patología General y su Clínica y el Curso de Clínica o Canon Perpetuo de Ciencia Médica. El Curso de Patología General y el Curso de Clínica constituyen las dos primeras partes de una trilogía inacabada, Tribiblión (Sarró Burbano, 1963), que 


FOLIA HUMANÍSTICA, Revista de Salud, ciencias sociales y humanidades
Núm.2 (Vol. 2) febrero-marzo 2020. ISSN 2462-2753

debería haberse completado con un tercer volumen sobre Historia de las ideas médicas. Algunos de sus libros están en la interfaz entre las humanidades y la medicina como el titulado Elementos de lexicología griega con aplicación al tecnicismo médico. Encontramos asimismo libros de divulgación científica y escritos políticos y morales como La Vanguardia Dinástica y la recopilación de algunas obras inéditas y otras publicadas en la prensa, que realizó su discípulo Rafael Forns con el título Obras Completas de José de Letamendi.

Destacan también sus discursos, en los que presenta las cuestiones científicas en su entorno filosófico e histórico más amplio, como corresponde a un autor de formación humanista. Así en los titulados Discurso acerca de los elementos generales de ciencia con aplicación al método en medicina (1866), Discurso sobre la naturaleza y origen del hombre (1867) y Valor de los estudios anatómicos en el movimiento intelectual contemporáneo, pronunciado en la inauguración del Curso Académico de 1877 a 1878 en la Universidad de Barcelona, al que nos referiremos más adelante.

\subsection{OBRA ARTÍSTICA}

Letamendi fue buen dibujante y pintor, como lo demostró con sus cuadros anatómicos presentados en la Exposición Universal de París en 1867. También fue compositor musical; escribió diversas obras, todas ellas celebradas, como una meditación para piano titulada El bien perdido, ¡Patria!, improntu a dos pianos, otra titulada Dies irae, partitura de salón, y una Misa de Requiem a grande orquesta, ejecutada por primera vez en el Monasterio del Escorial el 13 de setiembre de 1887.

Como crítico musical publicó diversos trabajos tales como La música del porvenir y El porvenir de mi patria. Fue entusiasta de Wagner, sobre quien realizó su trabajo Una cláusula negativa del testamento de Ricardo Wagner, que será traducido al alemán.

Letamendi fue además poeta, filólogo y políglota, matemático, ciencia que procuró hermanar con la Medicina, arqueólogo, historiador, gran prosista, y, en una palabra, un 
sabio cuyos profundos conocimientos se extendían a todas las ramas del saber humano.

\section{CRÍTICOS DE LETAMENDI}

\subsection{FAVORABLES}

Santiago Ramón y Cajal (1852-1934) fue alumno de Letamendi en la Facultad de Medicina de la Universidad de Madrid. Se refiere a él como «el gran José de Letamendi» (Sarró, 1963: 5) y, en su obra Recuerdos de mi vida, «el asombroso Letamendi» (id.:18). Rafael Forns y Romans (1868-1939), profesor de Higiene en Madrid desde 1908, escribe en el prólogo de su Curso de Higiene General: "En el terreno médico Letamendi fue el semidiós, como le tendrían por tal los venideros médicos si fuesen como los viejos atenienses, y yo no soy Letamendi, sino un catedrático de buen sentido, leal y honrado, que llamo a las cosas por su nombre"(Toledo, 2016).

El elogio que hace de Letamendi Mariano Batllés y Bertrán de Lis (1845-1922), catedrático de Anatomía de Barcelona, lo cita Ramón Sarró Burbano en los siguientes términos:

“...eminente anatómico, castizo literato, hábil cirujano, experto médico, correcto pintor, orador elocuente, maestro peritísimo, sagaz economista, sabio filósofo, competente sociólogo, músico inteligente, concienzudo matemático, erudito políglota, inspirado poeta; en una palabra, del hombre enciclopédico que con su inmenso talento, su vasta ilustración, y su imaginación calenturienta es el asombro de la generación actual, y lo será sin duda alguna de las venideras". (1963: 12-13)

Pero ahí se equivocaba don Mariano Batllés pues no tenía en cuenta que, o bien las generaciones venideras tendrían distintas percepciones y exigencias que las suyas, o bien que algún acontecimiento inesperado podría venir súbitamente a enturbiar la reputación de su admirado profesor. 


\subsection{DESFAVORABLES}

Entre los críticos que han valorado negativamente la obra de Letamendi se encuentran Pío Baroja (1872-1956), Gregorio Marañón (1887-1960) y Pedro Laín Entralgo (1908-2001). En su Historia de la Medicina, Laín Entralgo dice:

"Gozó de especial renombre como teórico de la medicina J. de Letamendi (1828-1897). Con su Curso de Patología General, obra compuesta al margen de lo que era la investigación científica del momento, pura especulación de gabinete, por tanto, Letamendi quiso ofrecer al médico una doctrina nosológica perennemente válida". (Laín, 1978:499)

Sospechamos que esta crítica puede estar basada en las opiniones de los dos críticos que le preceden en el tiempo, ya que no explica por qué la obra de Letamendi estaba escrita al margen de la investigación del momento ni cuál fuera esta. Gregorio Marañón en su libro Cajal, su tiempo y el nuestro (1951) abre de par en par la puerta de la polémica cuando, de manera demagógica y ambigua, escribe:

"Todavía no se puede nombrar a este extraordinario español sin un adjetivo apasionado. Para unos es la representación de la peor retórica anticientífica. Para otros, un genio, precursor de la medicina actual. Las dos opiniones son injustas. Letamendi fue todo lo gran patólogo que podía ser, sin ser un genio, pero con gran talento, en un país sin ambiente para la ciencia experimental. Es cierto que sus libros hoy no nos interesan. Pero tampoco nos interesan los de Conheim o los de Bouchard. Y hay algo en él que lo diferencia de los otros teorizantes de su tiempo, y es que si su doctrina marchaba con evidente retraso, sus ojos no estaban como los de los demás vueltos al pasado, sino clavados agudamente en el porvenir. Por eso Cajal que fue por su actitud y por su obra un anti-Letamendi, le trató siempre con respeto. $Y$ con respeto le debemos recordar ahora. Recordar, aunque no leer. Letamendi fue una figura representativa de una fase de nuestra vida intelectual que, solo eso, ya le haría interesante. Sin embargo estaba todavía dentro de la inopia científica. Aunque se reveló contra ella, procuró denodadamente superarla; $y$, en suma, fue el postrer ejemplar de la etapa de la triste esterilidad" ${ }^{2}$

Palabras duras que sólo pueden explicarse mediante un cambio en la episteme, en el modo general de ver a su país y a la ciencia. Pero, al igual que Laín Entralgo, Marañón escribe su crítica sin justificarla, sin indicar precisamente cuáles son esos

\footnotetext{
${ }^{2}$ Marañón, G. Cajal, su tiempo y el nuestro (1951; citado por Toledo Trujillo, 2016).
} 
motivos para que sus libros no nos interesen ya hoy. ¿Habría leído Marañón los libros de Letamendi? La pregunta queda en el aire, pero hemos de recordar que Marañón tenía una buena amistad con el primero de los críticos indicados, Pío Baroja. Ambos se retrataron juntos en varias ocasiones ${ }^{3}$, como en el acto de ingreso en la Real Academia de la Lengua Española de Pío Baroja, a cuyo discurso respondió Marañón y en Paris en 1939. Además, Baroja era uno de los intelectuales que frecuentaban El Cigarral, la finca toledana de Marañón y éste escribió el prólogo a la novela La Estrella del Capitán Chimista, de la serie Novelas del Mar, de Baroja.

Cabe pues la posibilidad de que las críticas de Laín Entralgo y de Marañón, ambas realizadas sin entrar en el detalle de la obra de Letamendi, fuesen hechas siguiendo la estela de Baroja. En consecuencia, volveremos a formular la pregunta anterior en el caso de Pío Baroja, alumno de Letamendi, a quien este había suspendido: ¿Habría leído Baroja con atención los libros de Letamendi? Ya lo veremos, pero como quiera que fuese, no puso freno a sus comentarios sobre él en, al menos, tres de sus obras. Comenzamos el análisis por una de las de mayor difusión.

En El Árbol de la Ciencia, Baroja escribe una larga parrafada en la que hace intervenir a quien fuera su profesor en la Facultad de Medicina de la Universidad de Madrid. Creemos que, para su valoración, merece la pena leerla completa, a continuación pues las palabras de Baroja:

"El año siguiente, el cuarto de carrera, había para los alumnos, y sobre todo para Andrés Hurtado, un motivo de curiosidad: la clase de José de Letamendi.

Letamendi era de estos hombres universales que se tenían en la España de hace unos años; hombres universales a quienes no se les conocía ni de nombre pasados los Pirineos. Un desconocimiento tal en Europa de genios trascendentales se explicaba por esa hipótesis absurda, que, aunque no la defendía nadie claramente, era aceptada por todos, la hipótesis del odio y la mala

\footnotetext{
${ }^{3}$ Algunos de estos retratos pueden verse en:

http://piobaroja.gipuzkoakultura.net/pio baroja irudi8.php y

https://www.diariovasco.com/v/20100316/cultura/admirado-amigo-unamuno-baroja-20100316.html https://elpais.com/elpais/2015/10/12/album/1444669947_989209.html\#foto_gal_3

(consultadas el 15/1/2020)
} 
fe internacionales que hacía que las cosas grandes de España fueran pequeñas en el extranjero y viceversa.

Letamendi era un señor flaco, bajito, escuálido, con melenas grises y barba blanca. Tenía cierto tipo de aguilucho, la nariz corva, los ojos hundidos y brillantes. Se veía en él un hombre que se había hecho una cabeza, como dicen los franceses. Vestía siempre levita algo entallada, y llevaba un sombrero de copa de alas planas, de esos sombreros clásicos de los melenudos profesores de la Sorbona.

En San Carlos corría como una verdad indiscutible que Letamendi era un genio; uno de esos hombres águilas que se adelantan a su tiempo; todo el mundo le encontraba abstruso porque hablaba y escribía con gran empaque un lenguaje medio filosófico, medio literario".

Así introduce Baroja a su profesor en la novela, como la caricatura de un hombre que vive en un país cerrado en sí mismo, ultramontano y cainita en el que predominaban extrañas hipótesis de odio y mala fe internacionales. Pero no contento con esto, prosigue:

"Andrés Hurtado, que se hallaba ansioso de encontrar algo que llegase al fondo de los problemas de la vida comenzó a leer el libro de Letamendi con entusiasmo. La aplicación de las Matemáticas a la Biología le pareció admirable. Andrés fue pronto un convencido.

Como todo el que cree hallarse en posesión de una verdad tiene cierta tendencia de proselitismo, una noche Andrés fue al café donde se reunían Sañudo y sus amigos a hablar de las doctrinas de Letamendi, a explicarlas y a comentarlas.

Estaba como siempre Sañudo con varios estudiantes de ingenieros. Hurtado se reunió con ellos y aprovechó la primera ocasión para llevar la conversación al terreno que deseaba y expuso la fórmula de la vida de Letamendi e intentó explicar los corolarios que de ella deducía el autor.

Al decir Andrés que la vida, según Letamendi, es una función indeterminada entre la energía individual y el cosmos, y que esta función no puede ser más que suma, resta, multiplicación y división, y que no pudiendo ser suma, ni resta, ni división, tiene que ser multiplicación, uno de los amigos de Sañudo se echó a reír.

- ¿Por qué se ríe usted? le preguntó Andrés sorprendido.

- Porque en todo eso que dice usted hay una porción de sofismas y de falsedades. Primeramente hay muchas más funciones matemáticas que sumar, restar multiplicar y dividir.

- ¿Cuáles?

- Elevar a potencia, extraer raíces... Después, aunque no hubiera más que cuatro funciones matemáticas primitivas, es absurdo pensar que en el conflicto de estos 
dos elementos, la energía de la vida y el cosmos, uno de ellos, por lo menos, heterogéneo y complicado, porque no haya suma, ni resta, ni división, ha de haber multiplicación. Además, sería necesario demostrar por qué no puede haber suma, por qué no puede haber resta y por qué no puede haber división. Después habría que demostrar por qué no puede haber dos o tres funciones simultáneas. No basta decirlo.

- Pero eso lo da el razonamiento.

- No, no; perdone usted, replicó el estudiante. Por ejemplo, entre esa mujer y yo puede haber varias funciones matemáticas: suma, si hacemos los dos una misma cosa ayudándonos; resta, si ella quiere una cosa y yo la contraria y vence uno de los dos contra el otro; multiplicación, si tenemos un hijo, y división si yo la corto en pedazos a ella o ella a mí.

- Eso es una broma, dijo Andrés.

- Claro que es una broma, replicó el estudiante, una broma por el estilo de las de su profesor, pero que tiende a una verdad, y es que entre la fuerza de la vida y el cosmos hay un infinito de funciones distintas: sumas, restas, multiplicaciones, de todo, y que además es muy posible que existan otras funciones que no tengan expresión matemática.

Andrés Hurtado, que había ido al café creyendo que sus proposiciones convencerían a los alumnos de ingenieros, se quedó un poco perplejo y cariacontecido al comprobar su derrota.

Leyó de nuevo el libro de Letamendi, siguió oyendo sus explicaciones y se convenció de que todo aquello de la fórmula de la vida y sus corolarios, que al principio le pareció serio y profundo, no eran más que juegos de prestidigitación, unas veces ingeniosos, otras veces vulgares, pero siempre sin realidad alguna, $n i$ metafísica, ni empírica".

Pero no indica Baroja cuál fue el libro de Letamendi que leyó Andrés Hurtado. La fórmula de la vida, Letamendi la publicó en un artículo (revista El Siglo Médico, en 1882) y no constituye, ni mucho menos, uno de los resultados principales de su obra. Sin embargo, Baroja regresará a la fórmula de la vida una y otra vez, haciendo de ella un punto clave para su crítica que crece desviándose para adquirir un tono ofensivo, mucho más rentable para un novelista que la difícil búsqueda de la objetividad:

"Todas estas fórmulas matemáticas y su desarrollo no eran más que vulgaridades disfrazadas con un aparato científico, adornadas por conceptos retóricos que la papanatería de profesores y alumnos tomaba como visiones de profeta.

Por dentro, aquel buen señor de las melenas, con su mirada de águila y su diletantismo artístico, científico y literario; pintor en sus ratos de ocio, violinista y compositor y genio por los cuatro costados, era un mixtificador audaz con ese 
fondo aparatoso y botarate de los mediterráneos. Su único mérito real era tener condiciones de literato, de hombre de talento verbal.

La palabrería de Letamendi produjo en Andrés un deseo de asomarse al mundo filosófico y con este objeto compró en unas ediciones económicas los libros de Kant, de Fichte y de Schopenhauer.

Leyó primero La Ciencia del Conocimiento, de Fichte, y no pudo enterarse de nada. Sacó la impresión de que el mismo traductor no había comprendido lo que traducía; después comenzó la lectura de Parerga y Paralipomena, y le pareció un libro casi ameno, en parte cándido, y le divirtió más de lo que suponía. Por último, intentó descifrar la Crítica de la razón pura. Veía que con un esfuerzo de atención podía seguir el razonamiento del autor como quien sigue el desarrollo de un teorema matemático; pero le pareció demasiado esfuerzo para su cerebro y dejó Kant para más adelante, y siguió leyendo a Schopenhauer, que tenía para él el atractivo de ser un consejero chusco y divertido.

Algunos pedantes le decían que Schopenhauer había pasado de moda, como si la labor de un hombre de inteligencia extraordinaria fuera como la forma de un sombrero de copa.

Los condiscípulos, a quien asombraban estos buceamientos de Andrés Hurtado, le decían:

- ¿Pero no te basta con la filosofía de Letamendi?

Si eso no es filosofía ni nada replicaba Andrés. Letamendi es un hombre sin una idea profunda; no tiene en la cabeza más que palabras y frases. Ahora, como vosotros no las comprendéis, os parecen extraordinarias".

Mediante esta versión de la leyenda negra letamendiana, abundando en el tópico del provincialismo y desacreditando a su profesor, Baroja intenta destruir la reputación de Letamendi en dos páginas de su novela. ¿Por qué? Primero, porque don José de Letamendi había suspendido en reiteradas ocasiones a Baroja, quien, por este motivo, tuvo que trasladar su matrícula a Valencia, en donde se encontró con Slocker, discípulo de Letamendi, que volvió a suspenderlo (Palafox, 1965). Imperdonable falta. Y segundo, porque estos párrafos aportan acidez, un ingrediente que es garantía de éxito en una novela. Pero se equivocaba Baroja: Letamendi sí que tuvo una idea profunda, como expuso en la conferencia de apertura del curso 1878-79 en Barcelona que veremos más adelante.

No obstante, todavía fue más lejos Baroja con su crítica en su autobiografía titulada Desde la última vuelta del camino (Baroja, 2006: 392-393) en donde leemos: 
En San Carlos corría como una verdad indiscutible que Letamendi era un genio, uno de esos hombres águilas que se adelanten a su tiempo. Todo el mundo le encontraba abstruso, porque hablaba y escribía con gran énfasis un lenguaje medio filosófico, medio literario.

Él se creía además un pedagogo, y un pedagogo genial.

El primer día de clase miró la lista y me llamó:

-Señor Baroja y Nessi.

Yo me levanté.

-Vamos a ver, señor Baroja -me dijo- : suponga usted que a usted sin haber leído ningún libro acerca de la cuestión, le preguntaran: ¿Qué es para usted la medicina? ¿Qué diría usted?

- Yo diría que es el arte de curar.

- Bien, a ver el señor Tal.

Y Letamendi llamó a otro alumno de la lista.

-Usted, ¿Qué diría?

El alumno, más avisado que yo, recitó la definición de Letamendi.

- ¿Ve usted-me dijo el profesor-, ve usted?

Y añadió después que a mí me pasaba como a la mujer que ha puesto varias ropas a secar en la buhardilla, sobre cuerdas y no sabe dónde están.

Yo estuve por decir: "veo que a usted le gusta la adulación; yo creí que tenía delante una persona seria y no una bailarina".

Letamendi era un audaz y un desaprensivo. Tenía el tupé de decir que, así como se cree que el río Guadiana desaparece en la tierra, la medicina de Hipócrates había desaparecido de la historia para aparecer con él. Hipócrates y Letamendi. Era mucha broma. El uno, todo observación y sencillez; el otro, todo palabrería y fuegos artificiales.

Letamendi-Hipócrates nos relataba una serie de anécdotas en las que intervenían sus amigos y él...

Y un poco más adelante indica con indisimulado orgullo:

"De la obra de Letamendi-Hipócrates ha quedado muy poco; yo, para mí, creo que no ha quedado nada. Todo era bluff, retórica y palabrería. Creo que la fama de Letamendi la he comenzado a demoler yo".

Baroja reconoce haber comenzado intencionadamente la demolición del prestigio de su profesor basándose en sus experiencias en clase (estaba en tercer año 
de su carrera y debía ser en torno a 1890, contando Letamendi entonces sesenta y dos o sesenta y tres años y Baroja, diecinueve). Sin indicar qué libros había leído de Letamendi, vuelve a criticar su "fórmula de la vida" (Idem: 393):

"Yo leí entonces el libro de este profesor, en que intentaba aplicar las matemáticas a la biología e inventaba una fórmula de la vida de la que saca corolarios. Me convencí de que aquello no eran más que juegos de prestidigitación unas veces ingeniosos, otras vulgares; pero siempre sin realidad alguna, ni metafísica ni empírica (...)

Su obra era una catedral de cartón, o, a lo más, de cemento armado.

Si se quisieran encontrar obras españolas del mismo carácter de audacia artificiosa de colosalismo y de poca base, habría que recordar los monumentos arquitectónicos de Gaudí, los cuadros cubistas de Picasso y algunas otras obras por el estilo. En cambio si se quisiera hallar en España la obra médica antónima a la de Letamendi-Hipócrates, se tendría que retroceder hasta Juan Huarte de San Juan, el médico vasco del siglo XVI, tan sencillo, tan observador y tan lleno de intuiciones geniales".

Baroja sigue sin mencionar el título del libro que dice haber leído y vuelve por sus fueros comentando la misma fórmula matemática que criticaba en El árbol de la ciencia, intrascendente en la carrera de Letamendi. Su crítica peca de lo mismo que él dice de Letamendi: juegos de prestidigitación unas veces ingeniosos, otras vulgares; pero siempre sin realidad alguna, ni metafísica ni empírica. En definitiva: audacia artificiosa de colosalismo y de poca base.

Y es que su crítica está realizada con más sentimiento que razón y se basa en una enemistad personal manifiesta, como él mismo reconoce. $\mathrm{Y}$ así más adelante (Baroja, 2006: 400-401) leemos:

"Entre tipos de jabalí, como Olóriz; locos, como don Benito Hernando; farsantes, como Letamendi, y cucos almibarados como Calleja, San Martín se distinguía como un profesor sabio y como un hombre amable.

$(\ldots)$

Era una pretensión tan grotesca, que daba risa. Las pequeñas mistificaciones del profesor catalán no se parecen nada a las reflexiones del griego. Hipócrates es todo observación y juicio firme; Letamendi, quincallería aparatosa de bazar.

Algunos me han preguntado: “¿Por qué esa enemistad contra Letamendi?” 
Letamendi era una mistificación, un bluff, y hasta un bluff de poco éxito, una de esas farsas que gustan en los países meridionales, en donde se cree que los gestos, las actitudes, las frases, tienen su valor no sólo en la política, sino también en la ciencia.

\section{$(\ldots)$}

Por la cuestión del valor científico de Letamendi estuve yo a punto de entablar una discusión privada con Ramón y Cajal, que él no aceptó.

\section{$(\ldots)$}

Para rematar:

Estoy convencido de que, si ahora o en una ocasión más propicia se formara una comisión internacional para examinar las obras de medicina importantes del siglo XIX, la obra de Letamendi sería rechazada como vana, artificiosa y hasta perjudicial.

Su fórmula de la vida es pura vacuidad; los corolarios que deduce de ella no valen nada.

Letamendi es un hombre que trata de revolucionar la patología general, y como no tiene una idea sobre ella que valga la pena, acaba haciendo un pequeño diccionario para el diagnóstico, que podría ser algo, si fuera auténtico y verídico; pero como no lo es, no tiene ningún valor".

Es curioso que esta idea falsa de la medicina resuelta con un diccionario para el diagnóstico la tuviera, lo mismo que Letamendi, Unamuno, que, en muchos conceptos, se parecía a él.

“Un amigo del profesor de Salamanca me contaba que éste le decía a su hijo:

- Toda la práctica de la medicina está en aprender el casillero.

- ¿Qué quería decir con eso? - pregunté yo.

- Con eso indicaba el arte del diagnóstico. "Tú ves, por ejemplo", añadía dirigiéndose a su hijo, "una persona que tiene fiebre, dolor de costado, esputo rojizo... Se marcan en el casillero los tres síntomas, y sale pulmonía, y se busca el remedio"

Esto es descubrir el Mediterráneo. Lo que pasa es que esto no es siempre lo corriente, porque si fuera así, tan bien como los médicos sabios harían el diagnóstico las porteras.

El diccionario de Letamendi, como el casillero de Unamuno, es una idea de portera. 
Por poco que haya uno ejercido la medicina, ha visto pulmonías sin esputo herrumbroso, sin fiebre alta y que matan al enfermo; fiebres tifoideas en que la elevación de la temperatura no tiene regularidad; gripes que se acaban por arte de magia, cuando menos se lo espera uno; diabetes donde no hay hambre ni sed; dolores violentos en la región del apéndice que no son de apendicitis, etcétera.

No quiero insistir más; pero creo evidente que el que lea el libro de Letamendi verá que es de una perfecta oquedad, y que el silencio absoluto del mundo científico por él está perfectamente legitimado.

El libro podrá servir para hacer discursos aparatosos de academia; pero para colaborar en la investigación científica o para tener una idea práctica de la profesión, no sirve para nada".

De esta manera concluye Baroja la crítica de Letamendi en su autobiografía.

Vuelve a la carga en el libro titulado Juventud, Egolatría, en donde dice (p. 111):

"Entre los profesores, uno que se creía un pedagogo, y un pedagogo genial, era Letamendi. En el libro citado, El Árbol de la Ciencia, he dicho lo que me parecía tal profesor, que tenía cierto talento de orador y de literato. Era este un escritor rococó como muchos catalanes. A veces hablaba en la clase de arte y pintura, pero siempre con un criterio absurdo. Recuerdo una vez que decía que pintar un ratón y un libro no podía ser asunto para un cuadro; pero que si en el libro se escribía el título "Obras de Aristóteles", y al ratón se le ponía royéndolo, ya, lo que no era nada, se convertía en asunto pictórico. ¡Buen asunto pictórico para un cuadro de bazar!

Esta manera de ser, nimia y de una ingeniosidad pueril, representaba a Letamendi. A Letamendi le pasaba como a casi todos los españoles de su tiempo, aún a los más célebres como Castelar, Echegaray, Valera...

Habían leído, poseían una gran memoria, pero creo que profundamente no habían comprendido nada. No tenía ninguno de ellos ese sentimiento trágico de la cultura y de sus obligaciones que han tenido, sobre todo, los alemanes. Casi todos ellos miraban la ciencia como puede mirarla un señorito andaluz, ingenioso $y$ malicioso".

Pero se equivoca de nuevo Baroja. Letamendi no era nimio ni pueril. Su concepto de la ciencia es mucho más amplio y completo que el de un señorito andaluz, y mucho más amplio y completo que el del propio Baroja.

La crítica que Baroja hace de Letamendi a lo largo de su obra es, en primer lugar, incompleta; y en segundo lugar, incorrecta. La crítica hasta aquí vista no puede admitirse como referida a la obra de Letamendi, cuyos títulos Baroja ni siquiera ha mencionado. Pero también es incorrecta porque no se basa en la lectura de sus obras 
sino en sus experiencias personales en clase. Baroja, cuarenta y cuatro años menor que Letamendi, pertenece a una generación distinta. Pero además, si bien es cierto que ejerció como médico en Cestona, nunca desarrolló labor alguna como científico, y la combinación de médico y escritor no garantiza la calidad de su crítica científica, perteneciendo ésta a un área diferente de la cual el mismo Baroja se confiesa ajeno cuando, también en sus mejorías indica (Baroja, 2006: 371):

"Tampoco podía con las disertaciones científicas largas, como, por ejemplo, las de Julio Verne, que era el autor que en mi época casi todos los chicos leíamos con preferencia. Cuando empezaba éste a decir que la estrella tal se encontraba a tantos millones de leguas de la tierra, y que un tren, marchando a una velocidad de tantos kilómetros por hora, tardaría tantos cientos de miles o de millones de años en llegar a ella, saltaba la explicación pedagógica sin ningún escrúpulo. Tampoco me entretenían las descripciones".

De manera que el autor-médico, que en tan alto grado posee esa cualidad de la mordacidad, óptima para un novelista y que le permite insultar libremente a su profesor, se está confesando asimismo contrario al espíritu científico, cuando dice que no le gustan las disertaciones científicas ni las descripciones. Pero hay otro rasgo aún más demostrativo de la escasa capacidad científica de Baroja y es cuando dice (Baroja, 2006: 237):

"Evidentemente, el mecanismo de la herencia sigue siendo desconocido, Las leyes de Mendel tendrán realidad en los guisantes de olor y en otras plantas; pero entre los hombres no la tienen. Las combinaciones son múltiples $y$, por ahora, toda la mecánica de los cromosomas no da gran luz".

Equivocándose completamente en su interpretación de las leyes de Mendel, cuya realidad se aplica por igual a hombres y a guisantes. Por muy eminente literato que sea, no está autorizado Baroja, según él mismo reconoce, para realizar una crítica científica. En ciencia la mordacidad no vale nada comparada con la objetividad. Y, no obstante, su crítica puede haber influido sobre la opinión de Marañón y la de Laín Entralgo, marcando la opinión que sobre Letamendi han tenido generaciones de estudiantes y lectores. Indiscutiblemente la opinión de Baroja ha influido en la de su 
sobrino, Julio Caro Baroja, que en el prólogo a la edición de los Cuentos (Baroja, 1973: 8), escribe:

"Tuvo, pues, mi tío, antes de los primeros y relativos éxitos, un choque bastante doloroso con los representantes de cierto doctrinarismo político, choque similar a los que había tenido antes, de estudiante, frente al doctrinarismo médico-filosófico, de un también famoso profesor de San Carlos: el Doctor Letamendi. Aquellos hombres de cátedra, Salmerón y Letamendi, no eran, en verdad (y digan lo que digan todavía algunas personas) grandes pensadores. Pero como tales pensadores ejercían su autoridad máxima”.

Pero se equivoca Caro Baroja. Letamendi era un gran pensador.

\section{CONFERENCIA DE APERTURA DEL CURSO 1878-1879 EN LA UNIVERSIDAD DE BARCELONA ${ }^{4}$}

En su conferencia titulada Valor de los estudios anatómicos en el movimiento intelectual contemporáneo, Letamendi propone al auditorio una visita al anfiteatro anatómico de la Universidad de Pavía, durante la ejecución de unos ejercicios de disección por Andrés Vesalio (1514-1564). En la audiencia hay un religioso que "tiembla por la fe y por la ciencia el día en que...pueda la ciencia divorciada de la fe trocarse en malignidad, y la fe separada de la ciencia resolverse en intolerancia”. El religioso es alter ego del propio Letamendi, que conoce los peligros de una ciencia sin religión: "Lo que Vesalio ignora y el nítido teólogo prevé, formará el testamento de esta época y el tema del gran conflicto de aquel siglo XIX que por breves instantes hemos abandonado".

Lo que sigue es un repaso metódico a la Historia de la Filosofía con la intención de poner de manifiesto el fundamento metafísico que tiene la ciencia. Comenzando por Francis Bacon (1561-1626), a quien responsabiliza de que "los cultivadores de las ciencias empíricas crean que ese instrumento metódico ha sido forjado y labrado en

\footnotetext{
${ }^{4}$ La conferencia se encuentra en Internet (http://diposit.ub.edu/dspace/handle/2445/3567), consultada el 17/12/2019). Se han transcrito algunos de sus párrafos en este apartado actualizando la grafía con acentos y puntuación contemporánea
} 
sus laboratorios de Física, y no en los altos talleres de la sana Metafísica, que es lo cierto".

Dedica varios párrafos a René Descartes (1596-1650), "genio militar del progreso, en el concepto de haber pasado solo, caballero en su propia fogosidad y sable en mano el puente de Belascoain de la asediada Naturaleza, al frente y buena pieza por delante de la columna cerrada de investigadores del siglo XVII", a quien responsabiliza, mediante una serie de deducciones del "lamentable absoluto divorcio entre los cultivadores de las ciencias morales y los investigadores de las ciencias físicas".

Para Letamendi este divorcio es inadmisible, puesto que:

"Filósofo es el hombre por naturaleza; para él constituye el filosofar una necesidad moral, y pues la Filosofía es, como tendencia, la resolución del problema de la naturaleza y la finalidad del ser en sí, resulta que la integridad de contenido es la condición esencial del verdadero filosofar; y no hay, por tanto, Filosofía posible como en ella falten Dios y la mitad moral del hombre, ni la hay tampoco aceptable, donde no se contengan la mitad material del hombre y el resto del universo mundo".

La situación planteada por Descartes se resuelve mediante una disyuntiva:

"Dos solos partidos en lo humano quedaban: uno, materializar el espíritu; otro, divinizar la materia. He aquí los respectivos papeles que en la Historia del Pensamiento desempeñan Locke y Spinoza: el primero ensayando la reducción de la inteligencia a meras sublimaciones de la sensibilidad; el segundo intentando fundir todo lo existente y posible en el solo y absoluto ser, a quien llamó Dios por no exonerar a la substancia única del más excelente de los tratamientos substantivos".

Pero llegamos a un punto en que:

"Para salir de este desequilibrio entre exceso de material y el defecto de ideas necesitábase la chispa del ingenio y el chispazo brilló en dos distintas cabezas y con matices luminosos de reciproco complemento.

(...)de un lado Goethe esboza en dos teorías correlativas la reducción de todas las variantes vegetales al prototipo "hoja» y la de todas las variantes del armazón animal al prototipo "vértebra»--de otro lado Hegel, convirtiendo la Filosofía en Historia y el contenido de ésta en una sola acción realizada por un solo ser, la "ldea», da pie a que el ideal orgánico de Goethe sea explicado por reducción a un mero incidente episódico de la evolución de esa "ldea», o Absoluto, en el tiempo y el espacio, quedando con este solidarismo de las teorías de Hegel y 
Goethe, formulada la identificación de todas las especies naturales en un solo arquetipo ideal histórico; - Lamarck, tomando pie de la metamorfosis de los insectos, da como un hecho real ese ideal histórico, no reparando en que si la larva se transforma en ninfa y ésta en insecto perfecto y luego los huevecillos que este pone no dan insectos perfectos sino otra vez larvas, no se ha hecho con tantas mutaciones más que bajar de un salto de la altura a que con tanta pena se subió;..."

Letamendi quiere ir a parar en su discurso al materialismo:

“...todas las dificultades a la reposición de la escala filosófica por solo el esfuerzo y la industria de nuestra razón, sin que la mano del Eterno la afiance por el peldaño superior, parecen disiparse como nocturna neblina al remontar del sol de estío;Schelling apremia de otro lado a los idealistas con un sistema filosófico más, mientras del suyo, Augusto Comte, obcecado de impaciencia hasta el extremo de caer en la aberración mecánica de que el vapor del entendimiento, puesto en absoluta libertad, daría más trabajo útil que refrenado por la contraposición de los principios racionales, lo suelta abriendo de par en par todas las válvulas, y llama al desatinado rugir de los escapes: "Filosofía positiva». Krause, menos enérgico, propone en lo más recio del desorden, un sistema filosófico en que, a condición de renunciar todo el mundo a su pudor intelectual, todos los pareceres se acomoden y reconcilien en una que llamó "Unidad armónica»; entretanto el ignorado Mayer sienta los fundamentos de la Termodinámica que, de una sola conmoción científica, coloca en sus asientos la Física universal, dando pie a la resplandeciente "teoría de las fuerzas constantes», que abarca en simplicísimo concepto la ecuación mecánica del Universo entero; y sólo falta que Bunsen y su compañero de enterramiento experimental salgan, como en efecto salen, a enseñar con su espectrómetro el modo de reconocer sin falla la composición química de las más apartadas nebulosas, cuya teoría mecánica quedaba por lo visto construida-y por vías bien diversas de éstos, un centenar de pacientes anatomistas aclaran de día en día los secretos de la evolución embrionaria, y la simplifican reduciéndola a la teoría de las fuerzas constantes y a la idea hegeliogoethica, y son éstas y aquéllas aplicadas por los psicólogos anglo-positivistas a los fenómenos anímicos y sociales, bajo un sentido determinista.

Pero...:

Hasta aquí todo ofrece -aún el mismo error- cierto carácter científico; empero la Política urge, el tiempo vuela y apremia, la teofobia tuerce y violenta el criterio final de la investigación, si no fuese por el secreto de la vida y la fijeza de las especies, la idea de Dios resultaría demostrativamente innecesaria".

El mayor exponente del materialismo estaba por llegar:

"De improviso una claridad como de fuego de Bengala alumbra el mundo de las ideas: a orillas del Támesis un hombre por todo extremo agudo, perseverante $y$ experto ha dado en el secreto de la vitalidad que anima la corteza terrestre: su nombre es Darwin;(...) 
Este es, Señores, el momento en que la idea anatómica, bajo la enseña del transformismo orgánico, toma una actitud resueltamente invasora y trascendiendo al Dogma, a la Filosofía, a la Enciclopedia, a la Política, aspira a sojuzgarlo todo, en nombre del ateísmo".

Y entonces será el momento de regresar al anfiteatro de Pavía y volver a encontrarnos con los personajes para ver cómo han cambiado con el tiempo. Así:

"Aquellos silenciosos filósofos humanistas y políticos, que tanta importancia daban a las enseñanzas anatomo-fisiológicas del protegido del invicto Carlos, son hoy el espíritu histórico invadido por el fatalismo, el espíritu económico empedernido por la legitimación del egoísmo y el espíritu político sofisticado, so-color de libertad, y reducido a la lucha de los partidos por la subsistencia propia, no por el bien de la patria y encaminado al más lógico despotismo; todo en virtud de esa «lucha por la vida», que se da como causa y efecto del desenvolvimiento de los individuos y causa y efecto, a su vez, del de las sociedades; $y$, finalmente, los barruntos de aquel sabio capuchino que con tanto interés seguía la palabra del creador de la ciencia anatómica, son hoy la alarma de la Iglesia, cuya cabeza visible, a duras penas entrevista bajo el capuchón del Vaticano, no disimula la alarma y el duelo que en su ánimo promueve el desatado influjo del anatomismo darwinista".

Y también:

\begin{abstract}
"Alemania, la que presume de gran maestra del pensamiento, abdica de sus creídos derechos, para hacer vestir a sus sabios la librea del ilustre sofista inglés: para ello ha sido poco apresurarse a vaciar en el molde del transformismo toda la literatura científica natural; el espíritu de Lutero, sintiéndose próximo a su fin, instituye a la Anatomía moderna en su heredera de confianza y no cesa de repetir al oído de los escritores alemanes: "iNo os detengan preocupaciones de orgullo nacional; no las gloriosas tradiciones filosóficas; no la conciencia de que atentáis al porvenir de la misma libertad política! Por mi sois lo que sois; yo muero y Roma subsiste: proclamad a Darwin: que esto es lo que conviene a la causa del partido»Y Alemania obedece a esa voz, como en su día obedecerá a la de Moltke, militarmente; $y$ después de haber aplicado el anatomismo darwinista a todas las materias y todas las cuestiones, lo proclama por boca del ingenuo, profundo y eruditísimo Hellwald, como criterio para la misma Filosofía de la Historia; pero por tan honrada manera, efecto de la independencia de su carácter, que, en la Introducción a la citada obra, declara sin vacilar que no se formen ilusiones sus compañeros de ideas materialistas con respecto al porvenir de la libertad; pues los principios transformistas, que él cree ciertos, sólo conducirán al más inclemente despotismo".
\end{abstract}

Para Letamendi la separación de religión y ciencia ha llevado con el paso del tiempo a un desastre: el materialismo. La teofobia ha retorcido y violentado el criterio final de la investigación, y la ciencia verdadera, que sólo estaba a salvo por el secreto 
de la vida y la fijeza de las especies, ha perecido en manos del transformismo. Estas son algunas de las ideas que tiene quien Baroja dijo que no tenía ideas.

\section{DISCUSIÓN}

La personalidad de Letamendi y su tarea científica se ha contemplado desde distintas perspectivas a lo largo de la historia. Por lo general, sus contemporáneos tienen opiniones muy favorables, excepto Pío Baroja, su alumno, cuarenta y cuatro años menor que él, quien presenta en sus escritos una enemistad personal reconocida y manifiesta. La opinión de Baroja ha influido, sin duda, en la de su sobrino, Julio Caro Baroja y ha podido influir también en Marañón, con quien Baroja mantuvo una estrecha amistad y, a más largo plazo, en Laín Entralgo, prevaleciendo así una valoración negativa de Letamendi, mantenida durante décadas con el concurso de estos autores. Pero la situación actual de la ciencia, altamente especializada, dependiente de la tecnología, en permanente busca de una rentabilidad económica y, a menudo, desprovista de un fundamento moral, reclama una revisión.

Sarró Burbano ha puesto el dedo en la llaga cuando dice:

"La posición a la que nosotros hemos llegado después de leer reiterada- pero no exhaustivamente los escritos médicos de Letamendi, es terminantemente opuesta a las tesis de Cajal y de Carreras, explícita una e implícita la otra, de que la máxima productividad y vocación de Letamendi hay que buscarlas fuera de la Medicina. Nosotros, por el contrario, consideramos a Letamendi como máxima encamación de la Medicina. Si no parece médico es porque hoy ha arraigado en todos nosotros la convicción de que sólo un especialista (en Oftalmología, o en Urología, o en Bacteriología, o en Medicina Interma, o en lo que sea) puede ser un gran médico. Presuponemos que ha dejado de ser posible, como en la antigüedad, que la genialidad se exprese como el cultivo de lo que la medicina tiene de general. Nada más alejado de la realidad. También un médico general puede ser un genio". (1963: 20)

Letamendi, más que un médico en el sentido contemporáneo del término, es un médico católico. Su ciencia no busca la especialización, sino el bien de sus semejantes. En su discurso de apertura del curso académico, 1878-1879 en la Universidad de Barcelona, indica que el error para él estriba en lo que denomina Panidentismo, que define de esta manera: 
"Todos los sistemas filosóficos posibles, de carácter absolutamente humano, o que para nada cuentan con la revelación, son fácilmente reductibles a uno solo, bajo la denominación de panidentismo" (Letamendi, 1878: 38)

Para Letamendi, la diferencia no está entre las distintas corrientes filosóficas o políticas. En su concepto católico de la ciencia no es posible el conocimiento sin caridad y más importante que el conocimiento es la sabiduría que depende, como decía San Agustín, del temor de Dios (San Agustín, 1957: 121).

Junto con Eugenio d'Ors y Juan Domínguez Berrueta (Cervantes, 2013), entre otros, Letamendi forma parte del conjunto de los intelectuales que se dieron cuenta de la invasión del darwinismo, advirtiendo de los peligros que hay en admitir la lucha por la vida y la supervivencia de los más aptos como principios biológicos. Para Eugenio d'Ors (1949:78), durante los años que nos preceden, el historicismo se ha puesto a la escuela del prejuicio evolucionista, que preside así la íntima devoción de cada una de sus compilaciones, lo que se reconoce en general relativismo, y en la gran preponderancia que dan a lo paleontológico, y hasta lo geológico. Para d'Ors, el darwinismo había introducido un nuevo lenguaje en la ciencia.

También el reverendo Charles Hodge, de Princeton, en su libro titulado What is darwinism? describe la principal aportación de la obra de Darwin. No se trata de la evolución, que es una idea desarrollada en Francia a lo largo del siglo XIX (Laurent, 1987), ni tampoco de la selección natural, una expresión sin sentido (Flourens, 1864; Cervantes, 2013; Cervantes y Pérez Galicia, 2015, 2017), sino que, como bien indica Hodge, se trata de otra cosa:

It is however neither evolution nor natural selection, which give Darwinism its peculiar character and importance. It is that Darwin rejects all teleology, or the doctrine of final causes. He denies design in any of the organisms in the vegetable or animal world. He teaches that the eye was formed without any purpose of producing an organ of vision ${ }^{5}$.

\footnotetext{
${ }^{5}$ Traducción al castellano: Ni la evolución ni la selección natural son las que dan al darwinismo su peculiar carácter e importancia. Es el hecho de que Darwin rechaza toda teleología, o la doctrina de las causas finales. Niega el diseño en cualquiera de los organismos en el mundo vegetal o animal. Enseña que el ojo se formó sin ningún propósito de producir un órgano de la visión.
} 
En su obra principal, lo que hace Darwin, y captaron tanto Charles Hodge como Letamendi, es rechazar toda la doctrina de las causas finales, que, como indica Letamendi, está en el origen de la metafísica, de la filosofía y de la ciencia. Darwin es el máximo exponente del materialismo y, partiendo de sus premisas, la ciencia queda convertida en religión, pero como dice Letamendi, en consecuencia: "Ios principios transformistas, que él cree ciertos, sólo conducirán al más inclemente despotismo". (Letamendi, 1878:33).

La crítica que hace Baroja ha podido tener gran influencia histórica, pero es incompleta y errónea y por eso necesita una revisión para rehabilitar la reputación y prestigio de Letamendi. Es incompleta porque ni siquiera menciona los títulos de sus obras y no se dirige a ninguna de ellas en concreto. Está equivocada, por varios motivos. En primer lugar, porque se basa en aspectos personales de la propia experiencia de Baroja como alumno de Letamendi y no en la obra de este. En segundo lugar, porque da mucha importancia a aspectos secundarios como la fórmula de la vida. En tercer lugar, porque dice que Letamendi es un hombre sin una idea profunda. Nada más lejano de la realidad. La idea profunda de Letamendi es que la medicina y la ciencia, que tienen su origen en la metafísica y en un sistema religioso, han de estar al servicio de la religión. Es la idea que tantos compartieron a lo largo de los siglos, que pone a la religión como base de la educación (Cervantes, 2020). Finalmente, se equivoca mucho Baroja cuando dice que Letamendi es nimio y pueril. El conocimiento de la Historia de la Ciencia que hay en su discurso prueba que Letamendi poseía una mentalidad histórica, filosófica y científica fuera de serie que, en las circunstancias actuales, merece mucha atención. La insistencia de Baroja en una crítica insultante a su profesor, unida a su tendencia anticlerical expresada a lo largo de sus novelas, levanta una cuestión que reclama atención para estudios posteriores: Más allá del tono mordaz y satírico de sus escritos ¿Habrá en la crítica de Baroja una intención de perjudicar a la difusión de esas ideas que Letamendi, sin duda tenía, y expresó claramente en su discurso de apertura del curso 1878-79 en la Universidad de Barcelona? Es posible puesto que en un momento dado Baroja indica: 
"La ciencia no puede estar nunca de acuerdo con la religión ni la religión con la ciencia"

(Interludios, V, 700; citado en Elizalde, 1975: 85).

Lo cual es opuesto a la idea que, como hemos visto, Letamendi tenía.

\section{BIBLIOGRAFIA}

Baroja, P. El árbol de la Ciencia.

https://arts.st-andrews.ac.uk/stancallit/arbol/p1c8.shtml (Consulta el 16/12/2019)

- (1985). Juventud, Egolatría, Madrid: Editorial Caro Raggio.

- (2006). Desde la última vuelta del camino. ISBN 10: 8483104776. Barcelona: Tusquets editores SA.

Cervantes, E. (2013). Manual para detectar la impostura científica. Examen del libro de Darwin por Flourens. ISBN-10: 1717000509 Amazon. Digital CSIC: https://digital.csic.es/handle/10261/76630 (Consulta el 15/1/2020)

- (2020). Un discurso inédito de Víctor Sainz de Robles en 1867. Príncipe de Viana, núm.26 (en prensa).

Cervantes, E.; Pérez Galicia, G. (2015). ¿Está usted de broma Mr Darwin? La retórica en el corazón del darwinismo. ISBN-10: 0692443118 OIACDI. Amazon.

https://app.box.com/file/336387830376 (Consulta el 16/1/2020)

- (2017). La nave de los locos. El Origen de las Especies a la luz de la nueva retórica. ISBN-10: 1981532110 OIACDI. Amazon. https://app.box.com/file/336383055757

(Consulta el 16/1/2020).

Elizalde, I. (1975). Personajes y temas barojianos. Universidad de Deusto.

Flourens, P. (1864). Examen du libre de Darwin sur l'Origine des Espéces. Paris: Garnier Frères, Libraires-Éditeurs. 
https://fr.wikisource.org/wiki/Examen du livre de M. Darwin sur 1\%E2\%80\%99origine des esp\%C3\%A8ces/Texte entier (Consulta el 16/1/2020)

Hodge, Ch. (1874). What is darwinism? Scribner, Armstrong, and Company. New York.

https://www.gutenberg.org/files/19192/19192-h/19192-h.htm (Consulta el 16/1/2020)

Laurent, G. (1987). Paléontologie et Évolution en France 1800-1860. Une histoire des idées de Cuvier et Lamarck à Darwin. ISBN: 2-7355-0126-4. Paris : Editions du Comité des Travaux Historiques et Scientifiques.

Letamendi y Manjarrés, J. (1878). Valor de los estudios anatómicos en el movimiento intelectual contemporáneo. Conferencia de apertura del Curso Académico de 1878 a 1879 ante el Claustro de la Universidad de Barcelona. http://diposit.ub.edu/dspace/handle/2445/3567

Letamendi y Manjarrés, J. (1907). Obras completas, Barcelona:edición de Rafael Forns. Establ. Tip. de F. Rodríguez Ojeda. http://diposit.ub.edu/dspace/handle/2445/13083

Laín Entralgo, P. (1978). Historia de la Medicina. ISBN: 84-345-1418-4. Barcelona: Salvat.

Palafox S. (1965). "Haz y envés del letamendismo neohipocrático". Medicina e Historia ,9: 315.

d’Ors, E. (1949). Nuevo Glosario. Vol III, 1934-1943. Madrid: Aguilar.

San Agustín. (1957). Sobre la Doctrina Cristiana. Tomo XV, edición preparada por el P. Fr. Balbino Martín, O.S.A. en: Obras de San Agustín. Madrid: Biblioteca de Autores Cristianos.

Sarró Burbano, R. (1963). El sistema Mecánico-Antropológico de José de Letamendi. Discurso de recepción en la Real Academia de Medicina de Barcelona.

http://ramc.cat/wp-content/uploads/2017/01/Ramon-Sarro-i-Burbano.pdf (Consulta el 16/12/2019)

Toledo Trujillo, F. (2016). Don José de Letamendi Manjarrés ¿Sabio investigador o tonto engreído? EGLE Revista de los cuidadores profesionales y las ciencias de la salud 4, 12-24. 
FOLIA HUMANÍSTICA, Revista de Salud, ciencias sociales y humanidades

Núm.2 (Vol. 2) febrero-marzo 2020. ISSN 2462-2753

José de Letamendi: fundamento de su ciencia y causa de su desprestigio

http://doi.org/10.300860/0066

Emilio Cervantes

http://historiaenfermeriacanaria.org/wp-content/uploads/2016/06/4 EGLE-n\%C3\%BAm-

4 primer-cuatrimestre-2016.pdf (Consulta el 15/1/2020)

\section{Emilio Cervantes \\ IRNASA-CSIC}

Emilio.cervantes@irnasa.csic.es

\section{Cómo citar este artículo:}

Cervantes, E., "José de Letamendi: fundamento de su ciencia y causa de su desprestigio", Folia Humanística, 2020; 2(2): 36-60. Doi: http://doi.org/10.300860/0066

(c) 2020 Todos los derechos reservados a la Revista Folia Humanística de la Fundación Letamendi Forns. This is an open access article. 